\title{
Desenvolvimento corporal e testicular em machos de codornas de corte e de postura de 25 a 360 dias $^{1}$
}

\begin{abstract}
Tatiana C. Santos ${ }^{2 *}$, Alice E. Murakami², Carlos A.L. Oliveira ${ }^{2}$ e Paula D. Costa ${ }^{2}$
ABSTRACT.- Santos T.C., Murakami A.E., Oliveira C.A.L. \& Costa P.D. 2012. [Body and testicular development in males of meat- and egg-type quails of 25 to 360 days.] Desenvolvimento corporal e testicular em machos de codornas de corte e de postura de 25 a 360 dias. Pesquisa Veterinária Brasileira 32(11):1205-1212. Departamento de Zootecnia, Universidade Estadual de Maringá, Av. Colombo 5790, Maringá, PR 87020-900, Maringá, PR, Brazil. E-mail: tcsantos@uem.br

Meat- and egg-type quails were analyzed to determine reproductive development, puberty and the onset of senility. For this purpose, 288 quails (144 meat- and 144 egg-type quails) were followed from hatch to 360 days old. The birds were distributed by age in 18 groups, 8 quails/group/type of quail. After 35 days quails were maintained under long daylength conditions (17L: 7D). The live weight and the macro and microscopical testicular characteristics were determined in each period. The data were analyzed to determine the growth curve and the behavior of parameters. The model that best fits the data was the non-linear Gompertz model ( $\mathrm{Y}=\mathrm{A}$ exp [-B and (-kt)]). Live weight and testicular morphometric parameters had an allometric behavior among themselves, and at approximately 60 days the males had sexually development, and body weight stabilized at about 100 days. The right testicle was more cranial than the left, differing in the length and width, but no difference in testicular weight $(\mathrm{P}>0.05)$ was observed. The meat quails had a larger body weight and testicular weight than the egg quails, but the egg-quail had a higher percentage of testes in relation to body weight. During the whole adult period the males could be considered sexually fit. Breeders had active sex characteristics until 360 days of age, represented by testicular size and by cellular activity in the seminiferous tubules.
\end{abstract}

INDEX TERMS: Quail, testicles, seminiferous tubules, Gompertz.

RESUMO.- Codornas do tipo carne e tipo ovos foram analisadas para determinar o desenvolvimento reprodutivo, a puberdade e o início da senilidade. Para tal, 288 codornas (144 codornas de corte e 144 de postura) foram acompanhadas desde a eclosão até os 360 dias de idade. As aves foram distribuídas por idade em 18 grupos, sendo 8 codornas/grupo/tipo de codorna. Após 35 dias as codornas foram mantidas em condições de fotoperíodo de dias longos (17luz: 7escuro). 0 peso vivo e os valores morfométricos e histológicos testiculares foram determinados em cada período. Os dados obtidos foram analisados para determinar a curva de crescimento e o comportamento dos parâmetros analisados. $\mathrm{O}$ modelo que mais se adequou aos dados foi

\footnotetext{
${ }^{1}$ Recebido em 24 de julho de 2012.

Aceito para publicação em 6 de setembro de 2012.

${ }^{2}$ Departamento de Zootecnia, Universidade Estadual de Maringá (UEM), Av. Colombo 5790, Maringá, PR 87020-900, Brasil. *Autor para correspondência: tcsantos@uem.br; E-mails demais autores: aemurakami@uem.br, caloliveira@uem.br, paulinhazoouem@hotmail.com
}

o modelo não linear de Gompertz ( $\mathrm{Y}=\mathrm{A}$ exp [-B e (-kt)]). 0 peso vivo e as características testiculares macro e microscópicas apresentaram comportamento alométrico entre si, sendo que, aproximadamente aos 60 dias os machos apresentaram-se sexualmente desenvolvidos, e estabilizaram o peso corporal por volta dos 100 dias. 0 testículo direito é mais cranial que o esquerdo e diferem em relação a comprimento e largura, porém não foi observada diferenças $(\mathrm{P}>0,05)$ para peso testicular. As codornas de corte apresentaram peso corporal e peso testicular maiores que as codornas de postura, porém as codornas de postura apresentaram peso relativo testicular maior. Durante todo o período analisado os machos puderam ser considerados sexualmente aptos. Os reprodutores apresentaram características sexuais ativas até os 360 dias de idade, representadas pelo tamanho testicular e pela atividade celular nos túbulos seminíferos.

TERMOS DE INDEXAÇÃO: Codornas, testículos, túbulos seminíferos, Gompertz. 


\section{INTRODUÇÃO}

As codornas são aves da ordem dos galináceos, Família Fasianidae e Gênero Coturnix. A codorna considerada doméstica é a codorna japonesa (Coturnix coturnix japonica), espécie para produção de ovos, enquanto a codorna européia (Coturnix coturnix coturnix) é destinada para a produção de carne (Murakami \& Ariki 1998). A criação de codornas, com finalidade de produção de carne e ovos, tem se tornado cada vez mais uma atividade de interesse econômico no Brasil. Em virtude de sua importância zootécnica, é necessário o esclarecimento de algumas características reprodutivas da espécie, considerando as variações de testosterona e a influência de fatores estacionais, que podem estar associados ao crescimento e à regressão dos testículos em resposta à luz, à temperatura e à disponibilidade de alimento (Kemp 1973).

O sistema reprodutor masculino das aves consiste de um par de testículos e pequenos epidídimos conectados aos ductos deferentes, os quais se abrem no urodeo, na cloaca. Nos machos de todas as espécies de aves, os testículos localizam-se no interior do corpo. São relativamente grandes em relação ao peso corporal e em muitas espécies há assimetria bilateral (Lake 1981). Nas aves domésticas estão localizados craniais aos rins e fixados à parede dorsal interna do corpo por uma dobra do peritônio. Essa posição dos testículos confere às aves a característica de realizarem espermatogênese a uma temperatura corporal interna de 40 a $42^{\circ}$ C. Nas codornas os órgãos reprodutores masculinos também obedecem a esse padrão (Froman, Kirby \& Proudman 2004).

Codornas expostas a variações sazonais de luz apresentam ciclo reprodutivo anual dividido em quatro fases, denominadas: repouso, recrudescência, proliferação e regressão. As fases sucedem-se ao longo do ano e apresentam o comprimento do fotoperíodo como principal influência exógena sobre sua frequência e duração (Baraldi-Artoni et. al 1997, 1999). A atividade hormonal nessas aves também reflete esta característica.

Apesar do grande número de trabalhos hoje disponíveis sobre a biologia da codorna, muitas lacunas ainda podem ser facilmente detectadas no conhecimento geral da espécie. Dessa forma, objetivou-se determinar a morfologia e o desenvolvimento dos órgãos genitais masculinos de codornas de corte e de postura dos 25 aos 360 dias de idade.

\section{MATERIAL E MÉTODOS}

O experimento foi conduzido na Fazenda Experimental de Iguatemi (FEI) pertencente à Universidade Estadual de Maringá e possui registro no Comitê de Conduta Ética no Uso de Animais em Experimentação, sob Parecer no 039/2008. Utilizou-se 288 machos de codornas, sendo 144 de corte e 144 de postura. As aves utilizadas foram acompanhadas desde o nascimento e criadas nos galpões do Setor de Coturnicultura da FEI.

Os pintainhos foram recriados em piso com cama de casca de arroz, recebendo ração de crescimento. Aos 15 dias foram debicados e aos 35 dias, após a sexagem, os machos foram criados como reprodutores, sendo que foram mantidos junto com as fêmeas em gaiolas de arame galvanizado, com área de $118 \mathrm{~cm}^{2} /$ ave, numa densidade de 6 fêmeas e 2 machos por gaiola, dessa forma rece- beram a mesma ração das fêmeas de postura, água ad libitum e regime de luz de 17 horas (natural + artificial). As rações do período de crescimento e de postura continham $23 \%$ e $20 \%$ de proteína bruta e 2.900 e $2.800 \mathrm{kcal}$, respectivamente, conforme recomendações do NRC (1999) e de Rostagno (2005).

Quando as aves atingiram as idades de 25, 30, 35, 41, 45, 50, $55,60,90,120,150,180,210,240,270,300,330$ e 360 dias, 8 machos de cada tipo de codorna foram sacrificados por decapitação entre o atlas e o occipital. 0 peso vivo e o peso testicular foram obtidos em balanças analíticas e o comprimento e a largura dos testículos direito e esquerdo foram mensurados com paquímetro digital. De quatro machos por idade os testículos foram colhidos e fixados em formaldeído $10 \%$ tamponado $(0,1 \mathrm{M}$ pH 7,4). Após a fixação, os fragmentos de testículos foram desidratados em concentrações crescentes de etanol (70\% a 100\%), em seguida diafanizados em xilol e incluídos em parafina. Cortes de 7 micrômetros foram obtidos em micrótomo e corados em Hematoxilina e Eosina. Os mesmos foram analisados em microscópio de luz no software Motic Images Plus 2.0 ${ }^{\circledR}$. Cada parâmetro foi obtido em 50 mensurações, divididas em 12 campos aleatórios, em pelo menos 6 cortes diferentes. Obtiveram-se valores para a altura do epitélio germinativo e para o diâmetro externo dos túbulos seminíferos em cortes transversais dos mesmos.

0 padrão de desenvolvimento de cada característica analisada foi ajustado a partir do Modelo não-linear de Gompertz ( $\mathrm{Y}=A$ exp $[-B e(-k . t)])$, sendo $e$ é a base do logaritmo natural $(e=2,71828)$, $A$ é a variável à maturidade, $B$ é a constante de integração sem interpretação biológica, $k$ é a taxa de crescimento em relação as variáveis à maturidade, ou seja, a velocidade com que o animal se aproxima da idade adulta e $t$ é a idade em dias. Os parâmetros do Modelo de Gompertz foram estimados pelo método de Gauss Newton modificado, preconizado por Regazzi, por meio do procedimento NLIN do SAS (Statistical Analysis System, versão 9.1.3).

Foram ajustados modelos de desenvolvimento para codornas de corte e de postura, dessa forma, com o intuito de avaliar as diferenças dos parâmetros das curvas de crescimentos, foram ajustados 8 modelos. 0 primeiro modelo é um modelo completo, sem nenhuma restrição no espaço paramétrico (modelo 1); três modelos com restrições de igualdade em um parâmetro, sendo em A (modelo 2), B (modelo 3) e k (modelo 4); outros três modelos com restrições de igualdade em dois parâmetros, sendo para A e B (modelo 5), A e k (modelo 6), B e k (modelo 7); e um modelo com igualdade em todos os parâmetros A, B e k (modelo 8). 0 teste para ajustamento dos modelos utilizados foi realizado conforme Regazzi \& Silva (2004).

Para analisar os dados nos indivíduos adultos, foram ajustadas regressões lineares simples do peso vivo, do peso testicular, do peso relativo dos testículos, do diâmetro do túbulo seminífero e da altura do epitélio germinativo em função da idade a partir de 90 dias utilizando o PROC GLM do SAS (Statistical Analysis System, versão 9.1.3).

\section{RESULTADOS}

A morfologia dos testículos em codornas do tipo corte e do tipo postura foi descrita ao longo da vida reprodutiva, dos 25 aos 360 dias de vida. Durante este período foram acompanhados o peso corporal e o peso relativo dos testículos, o comprimento, a largura e o peso dos testículos, e características microscópicas de altura do epitélio seminífero e diâmetro dos túbulos seminíferos. As equações resultantes destas análises estão representadas no Quadro 1 e as curvas de desenvolvimento de peso corporal, peso testicular e peso relativo dos testículos estão representadas na Figura 1. 
Com relação ao peso vivo, a análise das curvas de inflexão dos dados de peso vivo indicou que o desenvolvimento corporal das codornas machos do tipo postura estabilizou mais rapidamente do que em codornas do tipo corte
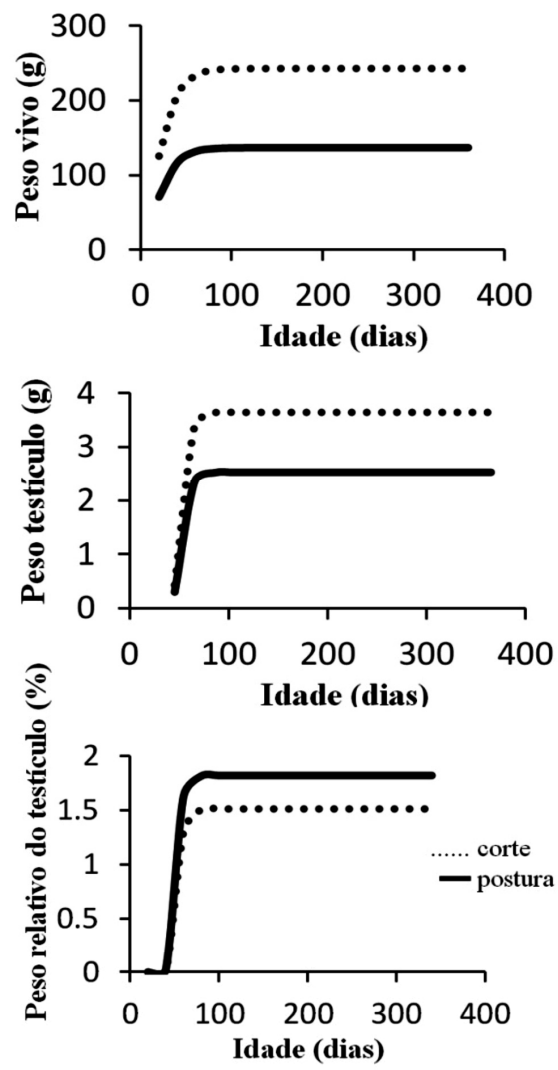

Fig.1. (A) Gráficos das curvas de crescimento corporal, (B) do peso testicular médio e (C) do peso relativo do testículo para machos de codornas de corte (.......) e de postura (-). Equações ajustadas no Quadro 2.
(Fig.1). 0 peso vivo tornou-se estável a partir dos 60 dias (Quadro 2). 0 peso vivo e o peso testicular foram superiores nas codornas de corte, quando comparado com as de postura, porém, apresentaram a mesma taxa de maturação, evidenciada pelo modelo 7 (Quadro 1). Em animais adultos, a partir dos 60 dias de vida, não houve diferenças no peso médio dos testículos $(\mathrm{P}>0,05)$ (Quadro 2)

Quando se analisou o peso relativo do testículo em relação ao peso vivo, em percentagem, as codornas de postura apresentaram médias de maior proporção testicular $(1,81 \%)$ do que as codornas de corte $(1,49 \%)$ (Fig.1, Quadro 1 e 2). As médias foram comparadas a partir de 60 dias, para se analisar o comportamento destes parâmetros ao longo da vida adulta das aves. 0 peso testicular e o peso relativo dos testículos não tiveram diferenças significativas $(\mathrm{P}>0,05)$ entre as idades estudadas, ou entre os lados direito e esquerdo.

0 comprimento e a largura dos testículos foram diferentes entre os testículos direito e esquerdo $(\mathrm{P}<0,05)$, tanto em codornas de corte quanto em codornas de postura.

Quadro 2. Média e erro padrão de variáveis corporais e testiculares de codornas macho de corte e postura dos 60 aos 360 dias de vida

\begin{tabular}{lrr}
\hline & \multicolumn{1}{c}{$\begin{array}{c}\text { Codorna } \\
\text { de corte }\end{array}$} & \multicolumn{1}{c}{$\begin{array}{c}\text { Codorna de } \\
\text { postura }\end{array}$} \\
\hline Peso vivo (g) & $240,86 \pm 2,78$ & $138,2 \pm 1,64$ \\
Peso dos testículos (g) & $3,59 \pm 0,08$ & $2,49 \pm 0,05$ \\
Peso relativo (\%) & $1,49 \pm 0,03$ & $1,81 \pm 0,03$ \\
Comprimento (mm) TD & $25,47 \pm 0,29$ & $22,48 \pm 0,28$ \\
Comprimento (mm) TE & $23,99 \pm 0,26$ & $20,66 \pm 0,25$ \\
Largura (mm) TD & $13,25 \pm 0,21$ & $13,68 \pm 0,66$ \\
Largura (mm) TE & $14,90 \pm 0,20$ & $13,11 \pm 0,25$ \\
Altura do epitélio seminífero (mm) & $64,07 \pm 1,54$ & $67,78 \pm 1,54$ \\
Diâmetro do túbulo seminífero (mm) & $232,56 \pm 3,95$ & $246,60 \pm 4,32$
\end{tabular}

TD - testículo direito, TE- testículo esquerdo

Quadro 1. Equações ajustadas para variáveis de testículo direito (TE) e esquerdo (TE) em codorna de corte e de postura

\begin{tabular}{|c|c|c|}
\hline Variável & Equações ajustadas & Modelo \\
\hline \multirow[t]{2}{*}{ Peso vivo } & Corte $=243,7 \times \exp (-2,6971 \times 2,71828(-0,0705 \times$ dias $))$ & 7 \\
\hline & Postura $=137,0 \times \exp (-2,6971 \times 2,71828(-0,0705 \times$ dias $))$ & 7 \\
\hline \multirow[t]{2}{*}{ Peso testicular médio } & Corte $=3,644 \times \exp (-3927,7 \times 2,71828(-0,1671 \times$ dias $))$ & 7 \\
\hline & Postura $=2,5323 \times \exp (-3927,7 \times 2,71828(-0,1671 \times$ dias $))$ & 7 \\
\hline \multirow[t]{2}{*}{ Peso relativo do testículo } & Corte $=1,5117 \times \exp (-7133,9 \times 2,71828(-0,1795 \times$ dias $))$ & 3 \\
\hline & Postura $=1,8202 \times \exp (-7133,9 \times 2,71828(-0,1843 \times$ dias $))$ & 3 \\
\hline \multirow[t]{2}{*}{ Comprimento TD } & Corte $=23,1154 \times \exp (-38,7395 \times 2,71828(-0,0909 \times$ dias $))$ & 7 \\
\hline & Postura $=25,6094 \times \exp (-38,7395 \times 2,71828(-0,0909 \times$ dias $))$ & 7 \\
\hline \multirow[t]{2}{*}{ Comprimento TE } & Corte $=21,1955 \times \exp (-19,8147 \times 2,71828(-0,076 \times$ dias $))$ & 7 \\
\hline & Postura $=24,2434 \times \exp (-19,8147 \times 2,71828(-0,076 \times$ dias $))$ & 7 \\
\hline \multirow[t]{2}{*}{ Largura TD } & Corte $=14,2615 \times \exp (-10,3217 \times 2,71828(-0,0596 \times$ dias $))$ & 3 \\
\hline & Postura $=13,6090 \times \exp (-10,3217 \times 2,71828(-0,0559 \times$ dias $))$ & 3 \\
\hline \multirow[t]{2}{*}{ Largura TE } & Corte $=13,4183 \times \exp (-53,8578 \times 2,71828(-0,0971 \times$ dias $))$ & 7 \\
\hline & Postura $=15,1036 \times \exp (-53,8578 \times 2,71828(-0,0971 \times$ dias $))$ & 7 \\
\hline \multirow[t]{2}{*}{ Compacidade TD } & Corte $=0,1403 \times \exp (-1219,4 \times 2,71828(-0,1518 \times$ dias $))$ & 7 \\
\hline & Postura $=0,1104 \times \exp (-623,7 \times 2,71828(-0,1376 \times$ dias $))$ & 7 \\
\hline \multirow[t]{2}{*}{ Compacidade TE } & Corte $=0,1526 \times \exp (-2138,5 \times 2,71828(-0,1641 \times$ dias $))$ & 7 \\
\hline & Postura $=0,1240 \times \exp (-902,9 \times 2,71828(-0,1457 \times$ dias $))$ & 7 \\
\hline \multirow[t]{2}{*}{ Altura do epitélio seminífero } & Corte $=68,3762 \times \exp (-208172 \times 2,71828(-0,2868 \times$ dias $))$ & 1 \\
\hline & Postura $=64,7148 \times \exp (-1253921 \times 2,71828(-0,3807 \times$ dias $))$ & 1 \\
\hline \multirow[t]{2}{*}{ Diâmetro do túbulo seminífero } & Corte $=248,3 \times \exp (-3722,9 \times 2,71828(-0,1922 \times$ dias $))$ & 1 \\
\hline & Postura $=232,1 \times \exp (-148465 \times 2,71828(-0,2783 \times$ dias $))$ & 1 \\
\hline
\end{tabular}

TD - testículo direito, TE- testículo esquerdo, exp = exponencial. 
Desta forma as curvas de desenvolvimento ao longo da vida das aves foram analisadas separadamente (Quadro 1). As médias do comprimento e da largura dos testículos direito e esquerdo nas codornas adultas (dos 60 aos 360 dias) estão representadas no Quadro 2.

Observando os dados dos testículos, a diferença morfométrica entre o direito e esquerdo para comprimento e largura refletiu a assimetria testicular, sendo o testículo direito mais longo e mais estreito, em comparação ao esquerdo, que foi mais curto e largo, com forma mais arredondada. Essa assimetria esteve presente mesmo em indivíduos jovens aos 25 dias e nos adultos, refletindo a ligeira diferença na posição que os mesmos ocuparam na cavidade celomática, sendo o testículo direito mais cranial do que o esquerdo (Fig.2).
A compacidade testicular (peso/comprimento) foi crescente, quando o animal atingiu sua idade adulta, depois estabilizou. 0 testículo esquerdo foi mais compacto e com formato mais arredondado que o direito, refletido nas medidas de comprimento, largura e compacidade testiculares apresentadas (Quadro 1).

Em relação aos aspectos microscópicos, o parênquima testicular esteve constituído por túbulos seminíferos e pelo compartimento intersticial intertubular. Em codornas jovens, no período de 25 a 40 dias, os testículos apresentaram túbulos seminíferos imaturos, sem luz, compostos por células de sustentação e espermatogônias. Nas codornas analisadas, aos 41 dias, alguns cortes possuíam luz e já se observaram algumas camadas de células de epitélio germi- corte
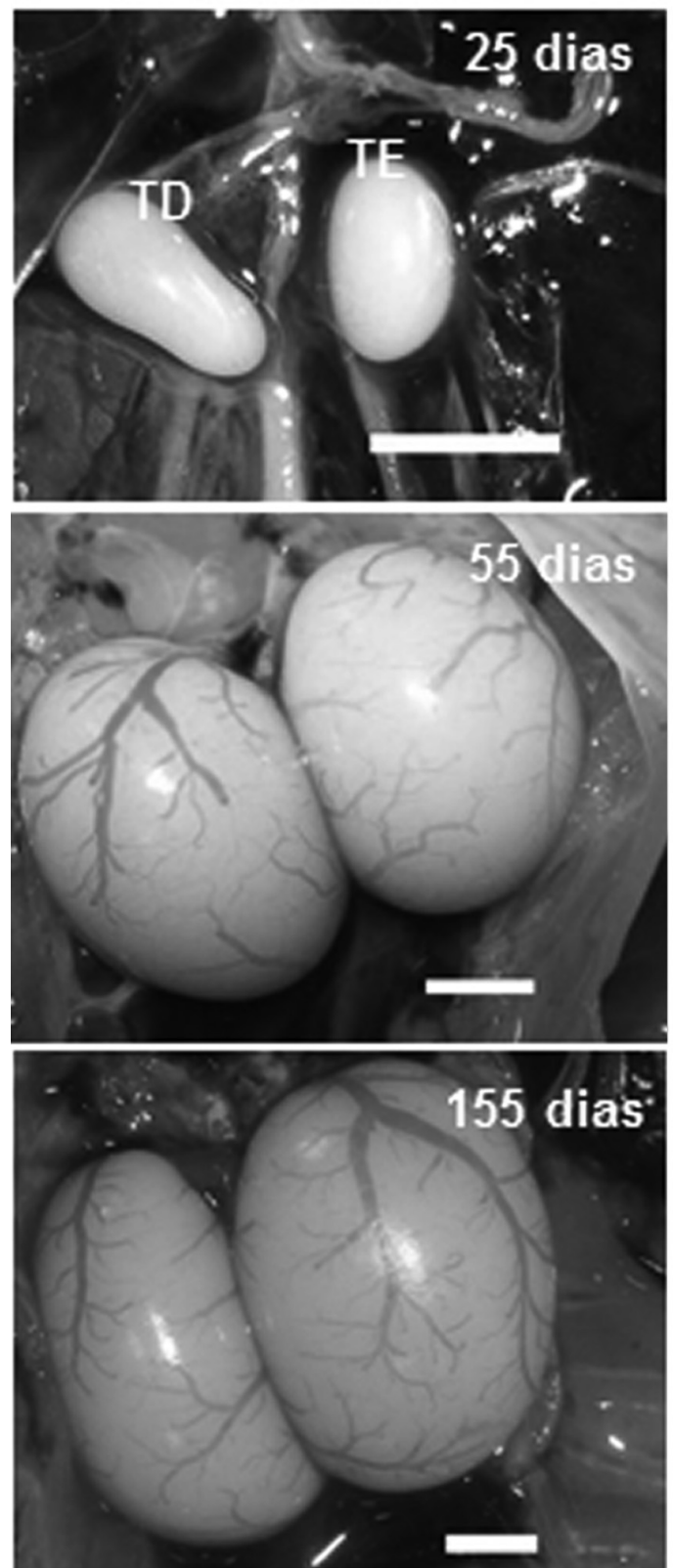

\section{postura}
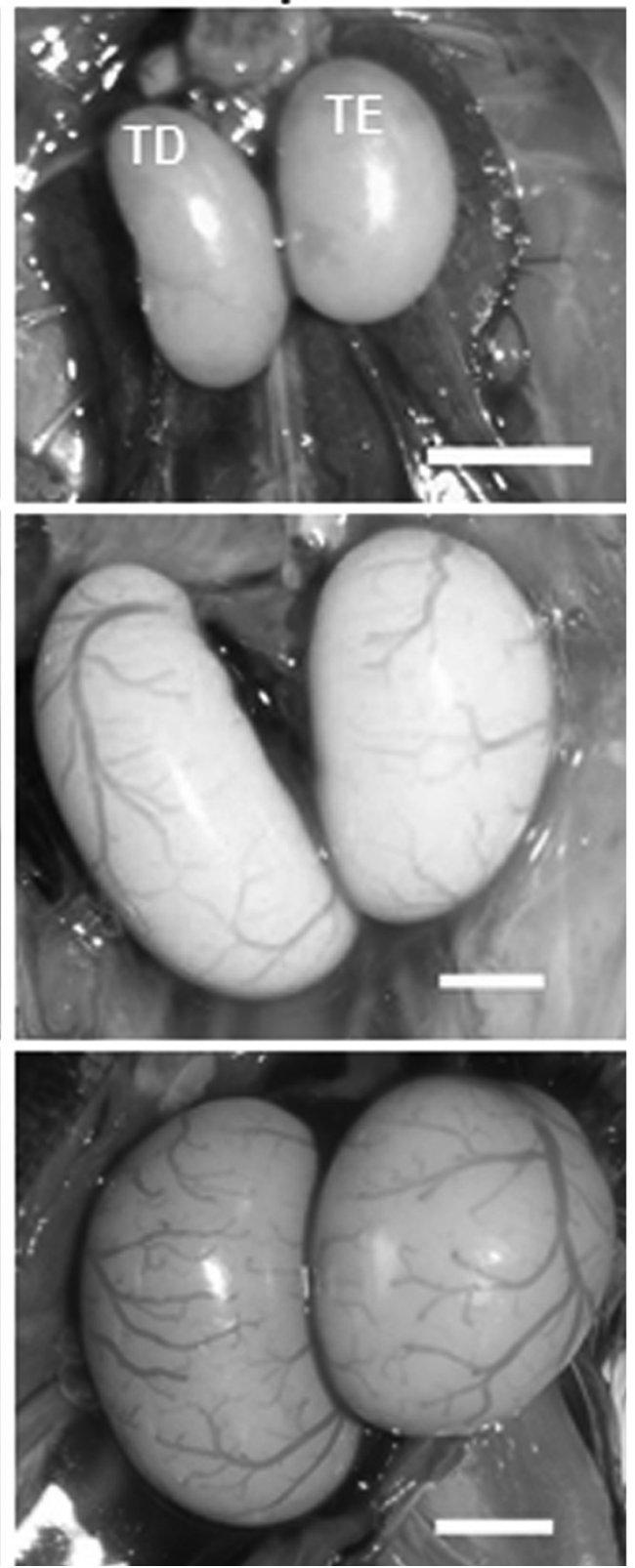

Fig.2. Vista ventral dos testículos direito (TD) e esquerdo (TE) in situ em codornas de corte e postura. Barra $=1 \mathrm{~cm}$. 


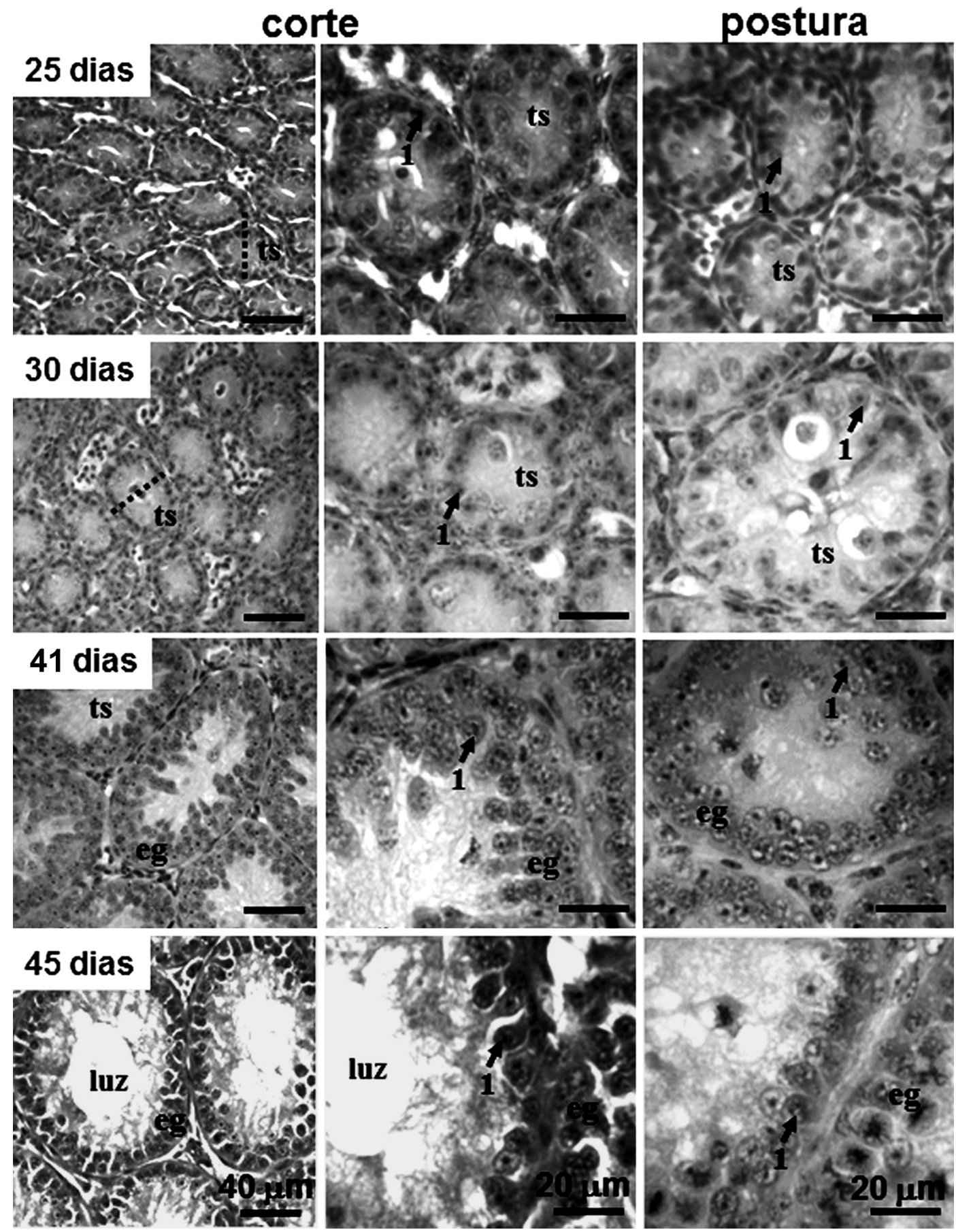

Fig.3. Testículos de codornas de corte (esquerda e centro) e de postura (direita) nas idades de 25 dias, 30 dias, 41 dias e 45 dias. Notar o rápido desenvolvimento dos túbulos seminíferos (ts) em diâmetro (-) em apenas 20 dias, a proliferação do epitélio germinativo (eg) composto por células de sustentação e espermatogônias (1), e a formação da luz tubular. Hematoxilina eosina.

nativo (Fig.3). Aos 45 dias todos os túbulos apresentaram lúmen definido e aos 50 dias, o epitélio germinativo estava completamente formado, com espermátides alongadas na luz dos túbulos (Fig.4).

0 epitélio germinativo dos túbulos seminífero das aves maduras sexualmente consistiu de dois tipos celulares: as células de sustentação e as células do epitélio seminífero, que constituíram a linhagem espermatogênica. A partir de 55 dias foram observadas todas as células da linhagem espermática, as espermatogônias, os espermatócitos primários, os espermatócitos secundários, as espermátides e espermatozóides livres na luz tubular (Fig.4). As mesmas características foram compartilhadas até os 360 dias, em ambos os tipos de codornas. Os espermatozóides caracterizaram-se pelo núcleo alongado e condensado, com cabeça em forma de vírgula e cauda alongada.

Em relação ao diâmetro do túbulo seminífero e à altura do epitélio germinativo, em ambas as espécies o crescimen- 

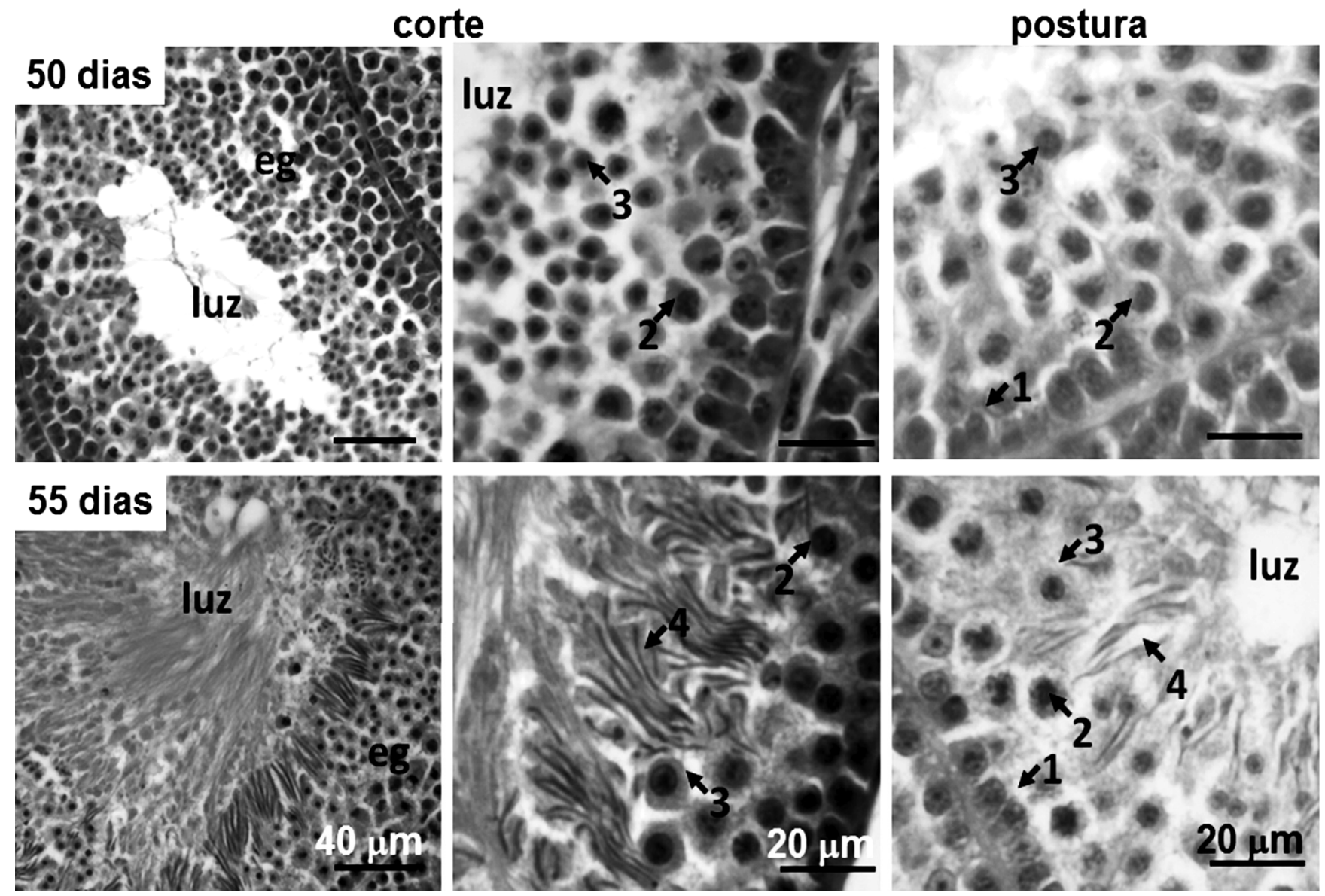

Fig.4. Túbulos seminíferos de codornas de corte e de postura nas idades de 50 e 55 dias. 0 epitélio germinativo (eg) está composto por várias camadas de células em que se identificam espermatogônias (1), espermatócitos (2), espermátides (3) e os espermatozóides (4) com núcleo alongado e cauda e direção à luz tubular.

to foi semelhante, observou-se que aos 25 dias as médias foram de $33,25 \mathrm{~mm}$ para o diâmetro do túbulo seminífero e $9,6 \mathrm{~mm}$ para a altura do epitélio germinativo, com o decorrer dos dias os valores aumentaram rapidamente, e a cerca dos 55 dias foram encontradas médias próximas a $227,64 \mathrm{~mm}$ de diâmetro e $64,87 \mathrm{~mm}$ de altura. A partir dos 60 dias as aves foram consideradas maduras sexualmente e os valores não diferiram estatisticamente até os 360 dias de idade (Quadro 2).

A altura do epitélio germinativo não foi influenciada pelo tipo da codorna, porém, nas codornas de corte observou-se uma redução da altura em função da idade a partir dos 90 dias, com uma taxa de $0,046 \mu \mathrm{m} /$ dia. 0 mesmo comportamento de redução foi observado para o diâmetro dos túbulos seminíferos, nas codornas de corte, com uma taxa de redução diária de $0,137 \mu \mathrm{m}$.

\section{DISCUSSÃO}

Em criações comerciais as codornas são criadas com fotoperíodo longo, para estimular a postura de ovos. As matrizes de codornas deste experimento receberam o mesmo manejo que as fêmeas a partir de 35 dias e desta foram os machos não apresentaram as variações sazonais observadas em aves criadas com luz natural. As codornas analisadas estabilizaram o peso corporal e os parâmetros testi- culares macro e microscópicos durante a vida adulta, até os 360 dias estudados, mantendo médias sem diferenças significativas ao longo deste período. Pode-se sugerir com esses resultados que as aves não reduziram o seu potencial reprodutivo até a idade estudada.

De modo geral, fotoperíodos longos em aves estimulam a maturidade sexual (Whittow 2000). 0 tamanho testicular aumenta durante a época de reprodução, diminuindo em estação não reprodutiva. Essas diferenças são mais visíveis em aves do que em mamíferos (Yoshimura 2004). Particularmente nas codornas, os machos apresentam um ciclo reprodutivo anual dividido em quatro fases, que se diferem com relação as estações do ano (Baraldi-Artoni et al. 1997, 1999).

Como em outras aves o fotoperíodo controla a reprodução em codornas (Sachs 1969). As aves usam ritmos circadianos para a percepção da duração do dia a uma fase fotossensível máxima que ocorre entre 11 a 15 horas depois de ligar as luzes. Nesta fase fotossensível ocorre um mecanismo neurohormonal que controla as funções reprodutivas. A luz é percebida por fotorreceptores hipotalâmicos que convertem o sinal eletromagnético em uma mensagem hormonal através de seus efeitos nos neurônios hipotalâmicos que secretam o hormônio liberador de gonadotrofina (GnRH). Nos machos as gonadotrofinas estimulam a pro- 
dução de espermatozóides e vários andrógenos, incluindo a testosterona. Dias curtos não estimulam a secreção adequada de gonadotrofinas porque não iluminam toda a fase fotossensível (Froman et al. 2004). Rutz et al. (2005) relataram que a redução de gonadotrofina ou de testosterona leva a degradação testicular. Dessa forma, acredita-se que ao controlar o fornecimento e a duração da luminosidade nas aves, possa-se estimular a reprodução.

Com relação ao peso corporal, as codornas de corte apresentaram peso corporal e testicular superiores as codornas de postura, porém quando se analisa o peso relativo, pode-se observar que nas codornas de postura o peso relativo dos testículos representou mais do peso total da ave $1,81 \%$, em comparação aos 1,50\% em média nos machos de codorna de corte. Analisando reprodutores de codornas de postura (japonesas) dos 70 aos 180 dias, Amoroso et al. (2008) relataram que o peso corporal não diferiu entre as idades e obtiveram uma média de $144,47 \pm 15,58 \mathrm{~g}$, peso relativo testicular de $2,08 \%$ e o peso testicular, com média de $3,00 \pm 0,51$, próximas as encontradas nesse trabalho, que foram de 3,59 $\pm 0,08$ para codornas de corte e $2,49 \pm 0,05$ para codornas de postura. Clulow \& Jones (1982) descreveram que em codornas maduras sexualmente os testículos podem representar cerca de $2,26 \%$ do peso vivo dos animais.

A curva de desenvolvimento do peso testicular, utilizando-se o modelo 7, sugeriu um crescimento alométrico, com o desenvolvimento testicular máximo ocorrendo antes do animal estabilizar o peso corporal, em ambos os tipos de codornas. Biswas et al. (2007) relataram uma alta e significativa correlação entre o peso testicular e os níveis de testosterona e de índice glandular para a glândula cloacal em codornas japonesas. Dessa forma, o peso testicular pode ser considerado um indicativo de fertilidade, uma vez que a redução no peso normalmente está associada à redução na espermatogênese e, portanto, na capacidade reprodutiva das aves, assim como na redução dos níveis de testosterona. Desta forma, apesar de neste trabalho não ter sido realizado dosagem de testosterona sanguínea ou estudos de fertilidade nas aves estudadas, o fato de não haver redução do peso testicular das codornas analisadas sugere que as mesmas mantiveram a atividade sexual até os 360 dias semelhante as demais idades.

A assimetria testicular observada nos machos de codornas de corte e de postura também pode ser descrita em outras espécies de aves. 0 mais comum em aves é que o testículo esquerdo seja o maior, mas ha exceções e aves com testículos proporcionalmente iguais, assim como espécies com o testículo direito maior (Lake 1981, Briskie \& Montgomerie 2007). Friedmann (1927) estudou 169 gêneros de aves silvestres e observou que na maioria dos casos os testículos possuíam tamanha semelhante, mas encontrou espécies em que ora o testículo esquerdo ora o direito eram maiores. Em galo, o testículo esquerdo é maior do que o direito em $67 \%$ dos galos, mas apresentam peso semelhante (Hocking 1992). Também nas aves estudadas por Marvan (1969) o testículo esquerdo era maior em 65,3\% dos casos. Sobre este aspecto Möller (1994) propôs que a alta qualidade reprodutiva dos machos estava relacionada com uma maior assimetria, no entanto esta hipótese tem sido des- considerada em trabalhos posteriores em que a habilidade reprodutiva dos machos não esteve associada a presença ou não da assimetria testicular (Birkhead et al. 1998).

Fisiologicamente, segund o Froman et al. (2004), a espermatogênese em aves consiste em um processo complexo de proliferação celular, redução haplóide e diferenciação celular, sendo que a duração estimada da espermatogênese em codornas é de 12,8 dias, tempo o suficiente para que uma espermatogônia se transforme em 32 espermatozóides.

As características do parênquima testicular nas codornas jovens e adultas estudadas foram também descritas por Froman et al. (2004) em outras espécies, com túbulos seminíferos com uma simples camada de célula de sustentação nos imaturos e em aves adultas encontraram-se com formato irregular alinhados por um epitélio germinativo de múltiplas camadas. Tanaka \& Yasuda (1980) realizaram estudos em galos observando as mudanças histológicas causados nos testículos. Os autores observaram que houve redução de células espermáticas e decréscimo no diâmetro dos túbulos seminíferos, assim como uma rápida redução do peso testicular, insinuando assim, a degeneração dos túbulos seminíferos em aves idosas.

Nas codornas analisadas, tanto nas de corte quanto nas de postura, as médias de altura do epitélio germinativo bem como o diâmetro dos túbulos seminíferos foram semelhantes durante a vida adulta até os 360 dias analisados, não havendo diferença $(\mathrm{P}>0,05)$, o que pode ser explicado pela constância de 17 horas luz durante a idade adulta, associado ao fato dos machos estarem todo o período com as fêmeas, estimulando a copulação e o comportamento reprodutivo.

Rospigliosi \& Figueroa (2003) analisaram os testículos de codornas japonesas durante as primeira 8 semanas de vida. Na terceira semana foram descritos espermatócitos primários e espermatogônias nos túbulos seminíferos e com 8 semanas citam que os testículos direito e esquerdo apresentaram comprimento médio de $5,2 \pm 1,3 \mathrm{~mm}$ e $4,5 \pm 1,0 \mathrm{~mm}$, respectivamente, porém sem espermatozóides nos túbulos seminíferos. Os autores não citaram detalhes da criação das aves, o que pode levar há variações consideráveis no surgimento da puberdade e na maturação sexual das aves.

No início da puberdade, o testículo nas aves passa por profundas modificações durante a espermatogênese e estas são muito semelhantes entre as espécies. Em galo domésticos, as primeiras 5 semanas, os túbulos começam a se organizar, multiplicando as células da camada basal (espermatogônias) e o início da puberdade é caracterizado pelo rápido aumento dos testículos e compleção dos espermatozóides (Johnson 1986). Em codornas fotoestimuladas, os espermatozóides podem ser detectados aos 26 dias no testículo e aos 30 dias no ducto deferente (Ottinger \& Brinkley 1979). Desta forma podem-se considerar as codornas em puberdade quando são observados espermatozóides na luz dos túbulos seminíferos. Nos reprodutores estudados, com programa de luz a partir de 35 dias, isso foi observado nos cortes histológicos aos 55 dias.

Estudos realizados nos meses de junho a outubro em codornas japonesas macho descreveram que o peso do tes- 
tículo variou de $2,80 \pm 0,16 \mathrm{~g}$ aos 70 dias para $3,28 \pm 0,48$ aos 120 dias, diminuindo para $2,93 \pm 0,98$ aos 180 dias de vida (Amoroso et al. 2008). Os mesmos autores citaram que a atividade espermatogênica máxima ocorreu na primavera, durante o período de 110-130 dias de idade, evidenciando que a fase de maior atividade reprodutiva coincide com o início do fotoperíodo crescente, ou seja, no final de agosto ao início de setembro. A atividade hormonal nessas aves também refletiu esta característica, sendo que no mesmo trabalho o pico de testosterona foi anterior à espermatogênese máxima, evidenciando a preparação do sistema reprodutor para a fase proliferativa. Nas codornas analisadas não foram observados comportamentos semelhantes.

\section{CONCLUSÕES}

Codornas de corte e de postura, criadas como reprodutores, em regime de luz de 17 horas a partir dos 35 dias, morfologicamente, apresentaram assimetria bilateral com testículo direito mais cranial e mais comprido que o esquerdo e, porém, não houve diferença quanto ao peso testicular. 0 peso corporal e os parâmetros morfométricos testiculares apresentaram comportamento alométrico entre si.

As codornas apresentaram características sexuais ativas dos 55 aos 360 dias de idade, representados pela estabilidade das variáveis morfométricas testiculares macro e microscópicas e pela atividade espermatogênica dos túbulos seminíferos. Dessa forma, até os 360 dias de idade, as características morfológicas testiculares dos machos de codornas de corte e de postura sugerem que estes são viáveis para a reprodução.

Agradecimentos.- Ao CNPq e Fundação Araucária pelo apoio financeiro.

\section{REFERÊNCIAS}

Amoroso L., Baraldi-Artoni S.M., Moraes V.M.B., Perecin D., Franzo V.S. \& Amoroso P. 2008. Influência da espermatogênese e dos níveis de testosterona no aspecto reprodutivo de codornas. Revta Bras. Zootec. 37(1): 61-66.

Baraldi-Artoni S.M., Orsi A.M., Carvalho T.L. \& Lopes R.A. 1997. The annual testicular cycle of the domestic quail (Coturnix coturnix japonica). Anat. Histol. Embryol. 26(4):337-339.

Baraldi-Artoni S.M., Orsi A.M., Carvalho T.L., Vicentini C.A. \& Stefanini M.A. 1999. Seasonal morphology of the domestic quail (Coturnix coturnix japonica) testis. Anat. Histol. Embryol. 28(4):217-220.

Birkhead T.R., Fletcher F. \& Pellatt E.J. 1998. Testes asymmetry, condition and sexual selection in birds: an experimental test. Proc. R. Soc. Lond. B 265:1185-1189.

Biswas A., Ranganatha O.S., Mohan J. \& Sastry K.V.H. 2007. Relationship of cloacal gland with testes, testosterone and fertility in different lines of male Japanese quail. Anim. Reprod. Sci. 97:94-102.

Briskie J.V. \& Montgomerie R. 2007. Testis size, sperm size and sperm competition, p.513-609. In: Jamieson B.G.M. (Ed.), Reproductive Biology and Phylogeny of Bbirds: Phylogeny, morphology, hormones, fertilization. Vol.6. The University of Queensland, Queensland.

Clulow J. \& Jones R.C. 1982. Production, transport, maturation, storage and survival of spermatozoa in the male Japanese quail, Coturnix coturnix. J. Reprod. Fertil. 64:259-266.

Friedmann H. 1927. Testicular asymmetry and sex ratio in birds. Biol. Bull. 52:197-207.

Froman D.P., Kirby J.D. \& Proudman J.A. 2004. Reprodução em aves: Macho e fêmea, p.237-257. In: Hafez B. \& Hafez E.S.E. (Eds), Reprodução Animal. 7aㅡ ed. Manole, Barueri.

Hocking P.M. 1992. Bilateral testicular asymmetry and supernumerary testes in the domestic fowl (Gallus domesticus). Brit. Poult. Sci. 33(2): 455-60.

Johnson A.L. 1986. Reproduction in the male, p.432-451. In: Sturkie P.D. (Ed.), Avian Physiology. $4^{\text {th }}$ ed. Springer-Verlag, New York.

Kemp A.C. 1973. Environmental factors affecting the onset breeding in some Southern African hornbills, Tockus spp. J. Reprod. Fertil. 19:319331.

Lake P.E. 1981. Male genital Organs, p.1-61. In: King A.S. \& Mclelland J. (Eds), Form and Function in Birds. Vol.2. Academic Press, London.

Marvan F. 1969. Postnatal development of the male genital tract of the Gallus domesticus. Anat. Anz. 124(4):443-462.

Möller A.P. 1994. Directional selection on directional asymmetry: Testes size and secondary sexual characters in birds. Proc. R. Soc. Lond. B 258:147-151.

Murakami A.E. \& Ariki J. 1998. Produção de codornas japonesas. Funep, Jaboticabal. 79p.

National Research Council - NRC 1994. Nutrient requirements of poultry. $9^{\text {th }}$ ed. National Academy of Sciences, Washington, D.C. 155p.

Ottinger M. \& Brinkley H.J. 1979. Testosterone and sex related physical characteristics during the maturation of the male Japanese quail (Coturnix coturnix japonica). Biol. Reprod. 20:905-909.

Regazzi A.J. \& Silva C.H.O. 2004. Teste pra verificar a igualdade de parâmetros e a identidade de modelos de regressão não-linear. I. Dados no delineamento inteiramente casualisado. Revta Mat. Estat. 22(3):33-45.

Rospigliosi J.D. \& Figueroa E. 2003. Desarrolho anátomo-histógico del testículo del nacimiento a la madures sexual de la codorniz (Coturnix cotur$n i x$ ) variedad japonesa. Revta Invest. Vet. Perú 14(1):74-78.

Rostagno H.S., Albino L.F.T., Donzele J.L., Gomes P.C., Oliveira R.F., Lopes D.C., Ferreira A.S. \& Barreto S.L.T. 2005. Tabelas brasileiras para aves e suínos: composição de alimentos e exigências nutricionais. $2^{\mathrm{a}}$ ed. Departamento de Zootecnia, UFV, Viçosa. 186p.

Rutz F., Anctuti M.A. \& Pan E.A. 2005. Fisiologia e manejo reprodutivo em aves, p.57-121. In: Macari M. \& Mendes A.A. (Eds), Manejo de Matrizes de corte. $2^{\underline{a}}$ ed. Facta, Campinas.

Sachs B.D. 1969. Photoperiodic control of reproductive behavior and physiology of the Japanese quail. Horm. Behav. 1:7-24.

Tanaka S. \& Yasuda M. 1980. Histological changes in the testis of the domestic fowl after adenohypophysectomy. Poult. Sci. 59(7):1538-1545.

Whittow G. 2000. Sturkie's Avian Physiology. Academic Press, San Diego. $685 p$.

Yoshimura T. 2004. Molecular bases for seasonal reproduction in birds. J. Poult. Sci. 41:251-258. 